\title{
ISCHEMIA, to revascularize or not to revascularize
}

\author{
Faraz Kureshi, MD, MSc, ${ }^{a}$ and Mouin S. Abdallah, MD, MSc ${ }^{\mathrm{a}}$ \\ a Saint Luke's Mid America Heart Institute, University of Missouri Kansas City, Kansas City, MO
}

Received May 19, 2016; accepted May 19, 2016

doi:10.1007/s12350-016-0557-5

\section{See related article, pp. 1690-1698}

Management of patients with coronary artery disease is focused on preventing cardiovascular events, improving survival, and control of anginal symptoms, and the cornerstone of treatment is optimal medical therapy with or without coronary revascularization. ${ }^{1}$ When these options of therapy have been compared among patients with stable ischemic heart disease, the benefits of coronary revascularization in addition to optimal medical therapy is not as clear as among patients with acute coronary syndrome. This is based on the results of several large randomized clinical trials that have failed to show a consistent superiority of one treatment strategy compared to the other. However, some results from observational studies have suggested that coronary revascularization may be superior to optimal medical therapy among patients with significant ischemia. ${ }^{2,3,4-7}$ The above-mentioned hypothesis served as the nidus behind the ongoing National Heart, Lung, and Blood Institute-funded ISCHEMIA trial (International Study of Comparative Health Effectiveness With Medical and Invasive Approaches; NCT01471522). In this trial, patients with stable ischemic heart disease and at least moderate ischemia will be randomized to optimal medical therapy with or without coronary revascularization to definitively answer the ongoing dilemma whether an invasive strategy with revascularization improves long-term outcomes in a randomized controlled trial.

\footnotetext{
Reprint requests: Mouin S. Abdallah, MD, MSc, Saint Luke's Mid America Heart Institute, University of Missouri Kansas City, Kansas City, MO; mouinabdallah2010@gmail.com

J Nucl Cardiol 2017;24:1699-701.

$1071-3581 / \$ 34.00$

Copyright (c) 2016 American Society of Nuclear Cardiology.
}

Although ischemia can be detected and quantified through multiple modalities, the richest data confirming the role of myocardial ischemia as a strong prognostic factor come from nuclear imaging. ${ }^{8-12}$ In this issue of the journal, Nudi et al reports a single-center, retrospective observational study evaluating the impact of coronary revascularization as compared to medical therapy on ischemia in patients undergoing serial stress- and rest-gated single-photon emission computed tomography (SPECT) myocardial perfusion imaging (MPI) studies. In order to better evaluate a cohort of patients with stable ischemic heart disease, patients were excluded if they had unstable angina in the prior 6 months, prior myocardial infarction, reduced left ventricular ejection fraction $(<45 \%)$, or a left ventricular end diastolic volume index $>130 \mathrm{ml} / \mathrm{m}^{2}$. Ischemia was semi-quantified by 2 experienced unblinded readers based on previously published (but not widely adopted) seven-region segmentation approach for left ventricular myocardium corresponding to a maximal ischemia score (MIS) group (no, minimal, mild, moderate, or severe ischemia). ${ }^{13}$ The authors identified a total of 3631 patients who underwent serial SPECT MPI between the years of 2004-2014 with 27\% $(n=967)$ undergoing coronary revascularization and $73 \%$ ( $n=2664)$ receiving only medical therapy at baseline. Multivariable adjustment and propensity score methodologies were used to minimize the effect of confounders. Unadjusted analyses revealed that revascularization was more effective than medical therapy in reducing myocardial ischemia in those patients with baseline moderate or greater MIS scores. All adjusted and propensity-matched analyses suggested a lower odds of a unit increase in MIS scores of patients who underwent revascularization as compared to medical therapy alone.

Given the observational nature of this study, several limitations should be noted. First, the study is subject to selection biases based on inclusion criteria and treatment assignment. Although the authors attempted to control for confounding using adjustment methods and 
propensity matching, there were several notable differences between those who were placed on medical therapy and those who received revascularization. This is clearly demonstrated in the propensity-matched analysis where the analytic cohort was reduced from 3631 to 732 patients, and the statistical significance of the results was less pronounced ( $P$ dropped from $<0.001$ for multivariable-adjusted analysis to 0.042 for propensitymatched analysis). Second, there were several important factors associated with management strategies that were not accounted for (chronic kidney disease, baseline angina status, prior revascularization by type, peripheral arterial disease, financial status, medication compliance), neither in the adjustment or propensity-matched groups. Third, when using propensity methodology, prior work has discouraged the use of statistical significance testing and suggested the use of standardized differences to assess the balance in propensity matching as this measure of distribution is not as sensitive to sample size as traditional testing. ${ }^{14,15}$ Fourth, there was no definition of optimal medical therapy or report of medication dosing, and it is certainly plausible that suboptimal medical therapy could have contributed to changes in ischemic burden on follow-up testing.

In spite of the above-mentioned limitations, the results from this analysis are similar to the prior reported sub-studies from the COURAGE and BARI-2D, which evaluated the effects of medical therapy and revascularization on ischemic burden. ${ }^{6,7}$ In the COURAGE substudy, patients underwent baseline and follow-up SPECT MPI, and it was found that revascularization in addition to optimal medical therapy resulted in a greater proportion of patients achieving the primary end point of $\geq 5 \%$ reduction in ischemic myocardium at follow-up (33\% vs $19 \%, P=0.0004)$, especially patients among those with moderate-to-severe baseline ischemia (78\% vs $52 \% \quad P=0.007)$. However, no differences were noted in adjusted death or myocardial infarction rates based on ischemia reduction. ${ }^{7}$ In the BARI-2D sub study, 1-year follow-up SPECT MPI was performed in 1505 diabetic patients with stable ischemic heart disease. It was found that a greater proportion of patients who received revascularization had no ischemia as compared with those assigned to optimal medical therapy $(59 \%$ vs $49 \%, P<0.001)$. Similar to COURAGE, myocardial ischemic severity was not an independent predictor of death or MI after adjustment. $^{6}$

As the ISCHEMIA trial is progressing in a slow fashion, having recruited only 3020 patients out of a goal of 8000 patients as of May 17th, 2016 (https:// www.ischemiatrial.org; accessed on May 17, 2016), we will have to wait for several more years to better understand the complex interaction between ischemic burden, optimal medical therapy, and coronary revascularization, and how these factors impact patient outcomes. In the interim, we should continue to follow current practice guidelines ${ }^{1}$ along with the Appropriate Use Criteria ${ }^{16}$ that have been vetted by the leaders in our field.

\section{References}

1. Fihn SD, Blankenship JC, Alexander KP, Bittl JA, Byrne JG, Fletcher BJ, et al. ACC/AHA/AATS/PCNA/SCAI/STS Focused Update of the Guideline for the Diagnosis and Management of Patients With Stable Ischemic Heart Disease: A Report of the American College of Cardiology/American Heart Association Task Force on Practice Guidelines, and the American Association for Thoracic Surgery, Preventive Cardiovascular Nurses Association, Society for Cardiovascular Angiography and Interventions, and Society of Thoracic Surgeons. Circulation 2014;130:1749-67.

2. Hachamovitch R. Does Ischemia Burden in Stable Coronary Artery Disease Effectively Identify Revascularization Candidates?: Ischemia Burden in Stable Coronary Artery Disease Effectively Identifies Revascularization Candidates. Circulation 2015;8:e00352.

3. Reynolds HR, Picard MH, Hochman JS. Does Ischemia Burden in Stable Coronary Artery Disease Effectively Identify Revascularization Candidates?: Ischemia Burden in Stable Coronary Artery Disease Does Not Effectively Identify Revascularization Candidates. Circulation 2015;8:e000362.

4. Hachamovitch R, Hayes SW, Friedman JD, Cohen I, Berman DS. Comparison of the Short-Term Survival Benefit Associated With Revascularization Compared With Medical Therapy in Patients With No Prior Coronary Artery Disease Undergoing Stress Myocardial Perfusion Single Photon Emission Computed Tomography. Circulation 2003;107:2900-7.

5. Aldweib N, Negishi K, Hachamovitch R, Jaber WA, Seicean S, Marwick TH. Impact of repeat myocardial revascularization on outcome in patients with silent ischemia after previous revascularization. J Am Coll Cardiol 2013;61:1616-23.

6. Shaw LJ, Cerqueira MD, Brooks MM, Althouse AD, Sansing VV, Beller GA, et al. Impact of left ventricular function and the extent of ischemia and scar by stress myocardial perfusion imaging on prognosis and therapeutic risk reduction in diabetic patients with coronary artery disease: Results from the Bypass Angioplasty Revascularization Investigation 2 Diabetes (BARI 2D) trial. J Nucl Cardiol 2012;19:658-69.

7. Shaw LJ, Berman DS, Maron DJ, Mancini GB, Hayes SW, Hartigan PM, et al. Optimal medical therapy with or without percutaneous coronary intervention to reduce ischemic burden: Results from the Clinical Outcomes Utilizing Revascularization and Aggressive Drug Evaluation (COURAGE) trial nuclear substudy. Circulation 2008;117:1283-91.

8. Shaw LJ, Hage FG, Berman DS, Hachamovitch R, Iskandrian A. Prognosis in the era of comparative effectiveness research: Where is nuclear cardiology now and where should it be? J Nucl Cardiol 2012;19:1026-43.

9. Shaw LJ, Min JK, Hachamovitch R, Hendel RC, Borges-Neto S, Berman DS. Nomograms for estimating coronary artery disease prognosis with gated stress myocardial perfusion SPECT. J Nucl Cardiol 2012;19:43-52.

10. Hachamovitch R, Hayes SW, Friedman JD, Cohen I, Berman DS. A prognostic score for prediction of cardiac mortality risk after adenosine stress myocardial perfusion scintigraphy. J Am Coll Cardiol 2005;45:722-9. 
11. Beller GA, Zaret BL. Contributions of nuclear cardiology to diagnosis and prognosis of patients with coronary artery disease. Circulation 2000;101:1465-78.

12. Berman DS, Abidov A, Kang X, Hayes SW, Friedman JD, Sciammarella MG, et al. Prognostic validation of a 17-segment score derived from a 20-segment score for myocardial perfusion SPECT interpretation. J Nucl Cardiol 2004;11:414-23.

13. Nudi F, Pinto A, Procaccini E, Neri G, Vetere M, Tomai F, et al. A novel clinically relevant segmentation method and corresponding maximal ischemia score to risk-stratify patients undergoing myocardial perfusion scintigraphy. J Nucl Cardiol 2014;21:80718.

14. Austin PC. An introduction to propensity score methods for reducing the effects of confounding in observational studies. Multivar Behav Res 2011;46:399-424.
15. Mamdani M, Sykora K, Li P, Normand S-LT, Streiner DL, Austin PC, et al. Reader's guide to critical appraisal of cohort studies: 2 . Assessing potential for confounding. BMJ 2005;330:960-2.

16. Wolk MJ, Bailey SR, Doherty JU, Douglas PS, Hendel RC, Kramer CM, et al. ACCF/AHA/ASE/ASNC/HFSA/HRS/SCAI/SCCT/ SCMR/STS 2013 Multimodality Appropriate Use Criteria for the Detection and Risk Assessment of Stable Ischemic Heart Disease A Report of the American College of Cardiology Foundation Appropriate Use Criteria Task Force, American Heart Association, American Society of Echocardiography, American Society of Nuclear Cardiology, Heart Failure Society of America, Heart Rhythm Society, Society for Cardiovascular Angiography and Interventions, Society of Cardiovascular Computed Tomography, Society for Cardiovascular Magnetic Resonance, and Society of Thoracic Surgeons. J Am Coll Cardiol 2014;63:380-406. 